\title{
La cesárea electiva podría disminuir la transmisión perinatal de HIV en mujeres que reciben profilaxis con AZT
}

Mandelbrot L, Le Chadenec J, Berrebi A et al. Perinatal HIV-1 Transmission. Interaction Between Zidovudine Prophylaxis and Mode of Delivery in the French Perinatal Cohort. JAMA.1998; $280: 55-60$.

\section{Objetivo}

Determinar el impacto de la modalidad del parto sobre la transmisión del virus de inmunodeficiencia humana (HIV-1) en presencia de profilaxis con zidovudina (AZT).

\section{Diseño}

Estudio prospectivo de una cohorte.

\section{Lugar}

Francia, 85 centros.

\section{Pacientes}

Se incluyeron 2834 niños nacidos de partos únicos de madres HIV- 1 positivas entre 1985 y 1996.

\section{Evaluación de factores pronósticos}

Se consignaron datos geográficos, edad materna, modo de adquisición del HIV, síntomas clínicos, recuento de CD4, Antígeno p24, carga viral del ARN-HIV-1, tratamiento antirretroviral, infecciones cervicovaginales, tipo de cesárea, inicio del trabajo de parto, integridad de membranas, y lactancia materna.

\section{Medición del resultado principal}

Infección por HIV de los niños nacidos de madres seropositivas.

\section{Resultados Principales}

De los 2819 embarazos incluidos, la profilaxis con AZT fue utilizada en 902 embarazos, y 1917 no la recibieron. Los partos por cesárea fueron indicados de urgencia en $10.9 \%$ de los casos y fueron electivos el $8.3 \%$, entendiéndose como cesárea electiva a su realización antes del inicio del trabajo de parto o la ruptura de membranas. El $17.2 \%$ de las madres que no recibieron AZT transmitieron a el HIV a sus hijos. Estos datos fueron obtenidos de 1877 de los 1917casos en los que no hubo profilaxis ya que del resto se desconocía la modalidad del parto. Los factores de riesgo asociados significativamente con la transmisión vertical fueron Ag p24 materno, infecciones cervicovaginales durante el embarazo, color del líquido amniótico, y ruptura de membranas de 4 horas o más, antes del parto. El modo del parto no se relacionó con la transmisión en este grupo de mujeres.

De las 902 madres que recibieron AZT, se pudieron obtener datos del parto en $872,6.4 \%$ transmitieron el HIV a sus hijos. En este grupo que recibió profilaxis, la cesárea electiva se asoció con menor índice de transmisión en relación con la cesárea de urgencia o el parto vaginal $(0.8 \%, 11.4 \%, 6.6 \%$ respectivamente; $\mathrm{P}=0.002)$. En un análisis multivariado* de todos los embarazos, la antigenemia p24 materna, la profilaxis con AZT y la interacción * entre modalidad del parto y profilaxis con AZT fueron variables asociadas indepedientemente a la transmisión vertical. Se realizó también un análisis multivariado de los embarazos que recibieron profilaxis con AZT, siendo los factores que correlacionaron con la transmisión: antigenemia p24 materna, color del liquido amniótico y modalidad del parto. Los índices de riesgo ajustado fueron: cesárea de urgencia 1.6 (IC 95\% 0.7-3.6); cesárea electiva 0.2 (IC 95\% 0.0-0.9; p=0.04) en comparación con el parto vaginal como referencia.

\section{Conclusiones}

La interacción* entre profilaxis con AZT y cesárea electiva resultó en una disminución de la transmisión vertical del HIV-1. El efecto beneficioso se observó principalmente en la población que recibió profilaxis y rea lizó cesárea electiva. Esta observación puede tener implicancias clínicas en estrategias de prevención.

\section{COMENTARIO}

En el presente estudio se ponen de manifiesto dos hechos contrastables y significativos: en presencia de profilaxis con AZT la cesárea electiva disminuyó en 5 veces el índice de transmisión, mientras que en ausencia de la administración de dicha droga el índice de transmisión fue similar para cualquiera de las modalidades (cesárea electiva, de urgencia ó parto vaginal). Mientras que ambos tipos de cesárea pueden tener impacto sobre la transmisión intraparto, la cesárea planeada puede evitar procesos fisiológicos y patológicos relacionados con el trabajo de parto e inclusive disminuír el riesgo de transmisión intraútero tardía. Aunque ninguno de los centros consignó la implementación de "cesáreas hemostáticas estrictas", los obstetras pudieron haber tenido mayores cuidados para evitar el contacto del feto con la sangre materna. Algunas de las hipótesis planteadas para explicar el hecho de la disminución de la transmisión en presencia de profilaxis más cesárea electiva son: 1) la infusión de AZT endovenosa comenzó 4 horas antes de la cirugía en las programadas mientras que en la cesárea de urgencia y el par- to vaginal la administración comenzó cuando el trabajo de parto ya se había iniciado; 2) el AZT es menos preventivo en el caso del parto vaginal en relación con la cesárea por su menor efecto sobre la excreción cervicovaginal del HIV con respecto a la carga viral sistémica. Contrariamente a ésta hipótesis el AZT ha probado ser efectivo para disminuir la excreción cervicovaginal del HIV, y su efecto sobre la carga viral sólo explica parcialmente la reducción en la transmisión. Finalmente si la cesárea programada disminuye el riesgo de transmisión del $6 \%$ al $1 \%$, deberían operarse a 20 mujeres para prevenir 1 caso (NNT). También es sabido que aunque la mortalidad del parto es muy baja, la cesárea incrementa la mortalidad materna 5 veces comparada con el parto vaginal, y las complicaciones postoperatorias son 3 veces más probables en las mujeres HIV+. Por lo tanto, es muy importante valorar el impacto de los factores obstétricos y de la terapia antirretroviral con nuevos estudios a fin de desarrollar e implementar nuevas estrategias para la prevención de la transmisión vertical del virus en todo el mundo. 